\title{
And What About the Family Back Home? International Migration and Happiness in \\ Cuenca, Ecuador
}

Fernando Borraz

Banco Central del Uruguay and Universidad de la República Montevideo, Uruguay

Susan PozO ${ }^{1}$

Western Michigan University • Kalamazoo, MI

Maximo Rossi

Universidad de la República • Montevideo, Uruguay

\begin{abstract}
In this study we use data on subjective well being and migration of family members in Cuenca, one of Ecuador's largest cities, to examine the impact of migration on the happiness of the family left behind. While a cursory examination of the data suggests that the heads of households that have experienced the migration of one or more family members are less happy, a more careful analysis reveals otherwise. Households that have been impacted by migration express equal levels of happiness as those households that have not been affected by migration. One plausible explanation for our finding is that the remittances that households receive following the migration of loved ones counteract the downsides to family emigration.
\end{abstract}

\section{Introduction}

International migration can be motivated by a number of factors. Some migrate in order to escape dire poverty. Others go into exile in search of religious or political freedoms. Some move to invest in education, others to join relatives abroad, and still others in pursuit of adventure and new opportunities. While a great deal of research has analyzed the short-run and long-run outcomes for those who move to new areas (e.g. Borjas, 2002; Chiswick, 2002; Smith, 2003; Card, 2005), in this paper we turn our focus to the family left behind. In particular, we consider whether international migration of one or more family members serves to increase or decrease the level of "happiness" of household members who remain in the home community.

Understanding how migration affects migrants and their families is of considerable interest given that migration will likely touch increasing numbers of individuals in the world. First, according to demographic information, the incidence of migration has been rising. In 1970, about 2.2 percent of the world's population lived 
in a country other than their country of birth. In contrast, by 2005, the foreign born accounted for 3 percent of the world's population. ${ }^{2}$

Second, emigration impacts more than those moving to another country. Legal, cultural, and monetary barriers to migration often make it difficult for whole families to migrate. The incidence of migration-impacted households can therefore easily change with public policy which ultimately accentuates family separations and dislocations. For example, Massey (2006) has noted that increased enforcement at the US/Mexico border - implemented to stem illegal immigration — has had the unintended effect of extending the stay of unauthorized immigrants who would normally periodically return home. Longer stays by unauthorized immigrant are likely to lead to longer-lasting and permanent family separations. A third reason for expecting migration to touch larger portions of the world population stems from policy shifts in immigration legislation toward preferences for skilled labor migration at the expense of family reunification. If legislation continues to be developed along these lines, it follows that a larger circle of individuals will be affected by migration due to longer-run family separations. Finally, rapid technological progress of the sort observed in the more recent decades is likely to continue, further reducing transportation and communication costs, easing travel, facilitating international migration and therefore increasing its incidence. ${ }^{3}$

Given the expectation of greater family dislocations via migration, what are our priors on the impact of migration on happiness? We hypothesize that migration reduces happiness levels of the family left behind. The emigration of a household member is likely to directly cause disruptions in the household since the absent household member may have been contributing to the household via market or home production. Thus, in addition to discomfort stemming from the absence of loved ones, household and monetary responsibilities now need to be assumed by other family members. The reallocation of household chores and market work is likely to be costly for the remaining family members, reducing happiness levels. It is also conceivable, however, that migration positively affects happiness levels. For example, as suggested and described by Cárdenas, Di Marco, and Sorkin (2009), the migration of family may increase the spatial dispersion of income sources. This, in turn, may raise the subjective well-being of the family because of the "insurance" this dispersion may buy, which, in effect, reduces the income vulnerabilities of the family.

In this paper we seek to examine the impact of migration on the happiness of the family left behind by exploiting information contained in the Discrimination and Economic Outcomes Survey undertaken in Ecuador in 2006. The survey contains information from 665 households: 480 in Cuenca and 185 in San Fernando. In this 
paper, we only include households residing in Cuenca because the San Fernando sample contains too few non-migrant households from which to draw the comparisons. Cuenca is the third largest city in Ecuador with nearly a half million inhabitants while San Fernando is a very small town with approximately 3,000 inhabitants. ${ }^{4}$ If the household does claim a migrant member, limited information on that migration is collected. Furthermore, a question that assesses the subjective well-being or "happiness" of the survey respondent is asked

Despite its geographic limitations, Cuenca is of interest to migration scholars owing to its long history of international migration to the United States. This migration was initiated shortly after WWII on account of the decline in use and therefore export demand for Panama hats (which despite the name, were produced in Cuenca and its surrounding areas in Ecuador). The hat manufactures in Cuenca had business contacts in New York, and when faced with declines in the traditional business, exploited those networks to migrate to the New York area. The subsequent development of those migration networks has produced significant migratory flows to the United States from the region (Gatton, 2005).

\section{Literature and Measurement Concerns}

Our intent is to try and measure whether international migration has impacted subjective well-being or happiness for the family remaining in the home community using the survey referred to above. ${ }^{5}$ Before outlining the methodology we use to link migration to happiness levels, it is appropriate to ask as to what extent is it possible to discern "happiness" from surveys such as the one in question? Di Tella and MacCulloch (2005) note that other social scientists including psychologists have relied upon happiness data much like the data included in the Discrimination and Economic Outcomes Survey that we are working with. They claim that, “. . . well-being data pass what psychologists sometimes call validation exercises." Pavot (1991), for example, finds that respondents who report that they are very happy tend to smile more, an act that arguably is correlated with true internal happiness. Layard (2005) further rationalizes the use of happiness data by noting research in neuroscience (Davidson, 2000) which has found that different regions in the brain are associated with positive and negative effects. Thus, when people describe their feelings there is some biological basis and their claims are not purely subjective. Furthermore, self-reported happiness is correlated with others' assessments of happiness. As such, many argue that happiness can be measured and can be compared between individuals and over time. 
We measure the respondent's well-being by considering whether he or she responded that he or she was "very satisfied," "fairly satisfied," "not satisfied," or "very unsatisfied" with his or her life. ${ }^{6}$

Table I presents some basic information on household heads in Cuenca along with their self described level of happiness as reported in the survey database. About 68 percent of household $(29+39)$ report that they are satisfied or very satisfied with their lives. We sum these two categories and classify these households as "happy." In contrast, we classify 32 percent of households as "not happy," as they claim to be either "not very satisfied" ( 29 percent) or "not at all satisfied" ( 3 percent) with their lives.

\section{Table 1}

Self-reported happiness levels of household heads in Cuenca, Ecuador

\begin{tabular}{lcc}
\hline Level of Satisfaction with Life & N & Percent \\
\hline Very Satisfied & 138 & 28.9 \\
Satisfied & 186 & 38.9 \\
Not Very Satisfied & 138 & 28.9 \\
Not at all Satisfied & 15 & 3.1 \\
\hline
\end{tabular}

The literature on happiness suggests that a number of demographic, cultural, and economic factors play a role in individual's happiness. A review of the empirical literature appears to concur with common expectations regarding the relationship between personal variables and happiness. For example, separated individuals and divorced individuals are found to be less happy (Clark \& Oswald, 1994; Blanchard \& Oswald, 2000). Happiness decreases with age but eventually rises as individuals get older. In contrast, education and happiness are found to be inverse u-shaped. More education increases happiness, but education can be "too much of a good thing," since beyond a certain point, additional levels of education are found to contribute negatively to happiness levels (Hartlog \& Oosterbeek, 1997).

Other variables are found to have less obvious and sometimes even counterintuitive impacts on happiness. For example, absolute income levels do not seem to be important as determinants of happiness (Easterlin, 1974; Blanchflower \& Oswald, 2000; Rayo \& Becker, 2007). Relative income or wage standing, instead, appear to affect happiness levels (Frank, 1985; Easterlin, 2001, Miles \& Rossi, 2007). Interestingly, self-employment is found to increase happiness for individuals in developed economies, while having the opposite effect for individuals residing in developing economies (Graham \& Pettinato, 200I). 
A number of other variables have been found to affect happiness, but with less robust findings. For example, while it has been reported that women are happier than men, the reported happiness among women is found to be declining over time. And while religious denomination does not appear to impact happiness, religiosity, measured by attendance at religious ceremonies, seems to be correlated with greater levels of happiness (Blanchflower \& Oswald, 2000).

Our intent is to contribute to this literature by assessing the impact of migration on happiness using the data from Cuenca, Ecuador. In an earlier publication, Cárdenas et al. (2009) explore this relationship using the Gallup World Poll survey and Latinobarómetro to analyze households from up to 20 Latin American and Caribbean countries. To this end, they estimate an equation of the following form:

$$
H_{i}=\alpha+\beta F_{i}+\delta M_{i}+\varepsilon_{i}
$$

and attempt to explain the happiness of respondent $i\left(H_{i}\right)$ which is presumed to depend on a vector of variables describing the characteristics $\left(F_{i}\right)$ of the household and respondent. The model is augmented with a migration related variable $M_{i}-$ for example, a dummy variable specifying whether or not the household claims that one of its members has emigrated. Of interest is the estimated value for $\delta$, the coefficient on the migration variable. The estimated value for $\delta$ along with information on its statistical significance is used to determine whether migration reduces, increases, or leaves unchanged the happiness of a family member left behind.

While (1) may seem a reasonable specification, we note that it may not be appropriate if one cannot justify that all right hand side variables in equation (1) are exogenous - that there is no correlation between the right hand side variables and the error term. This proves problematic for several reasons. Consider, for example, a very simple migration variable - a dummy variable assuming the value "l" for households that claim that one of its members is a migrant and " 0 " otherwise. Correlation between the migration dummy variable and the error term might very well exist on account of reverse causality. While we are presuming that migration impacts happiness (e.g., family remaining behind miss the migrant and perhaps their former contributions), it is also conceivable that happiness affects migration. For example, a very unhappy household head may "drive family away."

In addition to endogeneity originating from reverse causality, unobserved heterogeneity may also play a role. Migrant households are not likely to be randomly selected from the population, and it may be difficult to observe and control for that selection. ${ }^{7}$ For example, it may be that migrants tend to originate from households 
willing to indulge in risk-taking behavior. But risk attitudes may also play a role in determining happiness. If we cannot control for risk attitudes on the right hand side of (1), the migration variable and error term will be correlated and our inferences regarding migration and happiness will be biased.

Non-migration regressors in equation (1) may also suffer from endogeneity. One obvious candidate is income. Positive work attitudes may very well be a factor in determining income, but work attitudes are also likely to affect happiness. If we do not observe and, therefore, control for work attitudes, this will be reflected in the error term which will now be correlated with income, biasing the coefficient on income and incorrectly assessing income's impact on happiness.

Cárdenas et al (2009) conclude that, overall, households are made better off by migration. But they also note that household's subjective well-being appears to vary according to their vulnerabilities. Households that are nutritionally vulnerable are made worse-off by migration. While these results are interesting and have made in-roads into the issue of migration's impact on happiness level, we argue, as do Cárdenas et al. (2009), that endogeneity has not been accounted for in the above methodology, thus, bringing into question the final conclusions.

Our intent is to analyze migration's impact on happiness using the data from Cuenca, Ecuador, while accounting for the endogeneity problem discussed above. A common solution for endogeneity is to find instruments for the endogenous variables in question. By finding variables that are correlated with the endogenous right hand side variable yet not related to the dependent variable, we can purge the effects of endogeneity and thereby obtain consistent estimates that reliably describe how the right hand side variables affect happiness. In many cases, however, instruments are difficult to obtain. Furthermore, once we find what may appear to be a reasonable candidate, diagnostic tests of its suitability are sometimes of questionable reliability, making it difficult to justify its use. While we might venture to use instrumental variables to correct for one endogenous regressor, we feel less confident about finding and justifying instruments for all the regressors in equation (1) that are likely to be endogenous. For this reason, we seek an alternative technique to assess the impact of migration or migration related variables on happiness.

\section{Methodology}

The gold standard for assessing causality from variable " $M$ " (for example, the migration of household members) to outcome variable "H" (in our case happiness) is to perform a randomized experiment. In a randomized experiment subjects 
are chosen at random from the population. We refer to the random sample as the experimental or treatment group. Since these subjects have been selected at random, they must be, on average, identical in characteristics to the "control" group. The experimental group is then "treated" with migration. Next, we compare outcomes (e.g. happiness) in the experimental group with the control group. Any differences observed in the two can be attributed to the treatment since the two groups were identical before treatment. In this manner we avoid the selection bias problem, permitting us to assess causality from treatment $M$ (having a migrant family member) to outcome $\mathrm{H}$ (happiness).

Unfortunately, controlled random experiments are expensive and less likely to be undertaken in studies of international migration. ${ }^{8}$ As a substitute, we employ a matching technique - we in effect find a "control group" that matches the "experimental group" - the set of families who have been touched by migration. That is, we simulate a randomized experiment by finding a control group among those households who are not migrant households. We work backwards in comparison to a randomized experiment. We are presented with a treated group. Our job is to find a control group that matches the treated group and use the "matched control" group to derive comparisons with the "treated" group. In this way we can discern causality from migration to happiness and thereby make inferences about the effect of migration on happiness. While such a technique limits our conclusions (we do not get any information concerning how the other variables - e.g., income, age, education affect happiness), potential endogeneity on the part of these other variables will not compromise our conclusions about migration on happiness. In this way we eliminate selection bias that exists with respect to the comparisons of treated and non-treated groups and assess causality from " $\mathrm{M}$ " to " $\mathrm{H}$ " — in our case, from migration to happiness.

We use propensity score matching (PSM) to obtain an artificially generated control group that is similar to the treatment group in every aspect except that the persons in the control group do not have a family member abroad. Rosenbaun and Rubin (1983) show that it is not necessary to perform the match with respect to the vector of personal characteristics. It is enough to match the propensity score, that is, the predicted probability of treatment receipt (migration). We assume that treatment participation depends on a vector of observable variables $X$. In order to obtain the artificially created control group, one needs to first obtain the propensity score for each observation that "orders" observations along a set of observable variables. For each treated observation we find the non-treated observation that is closest to the treated observations to serve as the corresponding control observation. That is, we obtain 
predicted probabilities from a probit that predicts migration and then use these predicted probabilities to match non-migrant households to migrant households.

Typically, for each treated observation, PSM selects one similar non-treated observation and adds this observation to the control group. In our case, we use the $\mathrm{K}$-nearest neighbor matching method (setting $\mathrm{K}$ equal to 1 or more) to select the matched control group. Setting $\mathrm{K}$ to (say) 1 or 2 controls involves a tradeoff. Bias will be smallest with one matching observation (with $\mathrm{K}=1$ ), but we can reduce the variance if we choose $\mathrm{K}$ to be larger and hence choose more matches per treated observation. As we explain in more detail below, we choose $\mathrm{K}$ based on the size of the available control group. The actual algorithm employed to match the potential control observations to the treated observation is PSMATCH2, version 3.0 .0 by Leuven and Sianesi (2003).

\section{Hypotheses and Data}

Our prior is that migration reduces happiness levels for the family left behind. This prior is based on the notion that migration, and in particular international migration, disrupts the family. Mothers and fathers long for their children and children miss their siblings and parents. Grandparents regret missing grandchildren's milestones. Nieces and nephews yearn for advice from a favorite aunt. Disruptions to the family, however, may extend beyond "missing the company" of a loved one. For example, family chores that had previously been undertaken by the migrant need to be assumed by remaining family members. The monetary resources of the household may also be strained owing to the possibility that the household financed the migration. Or it may be that the previous income contributions of the now absent household member are missed.

In order to get a preliminary sense of the impact of migration on happiness, we tabulate the proportion of "migrant household" who report that they are "happy" relative to non-migrant households. We define the head to be happy if he or she reports that he or she is very satisfied or somewhat satisfied with life. These simple descriptive statistics are presented in Table 2. In the top portion of the table we divide households into those that claim to have at least one migrant member and those with no migrants belonging to the household. Migrant households appear less happy in the aggregate as the percent that claim to be happy is significantly less at the $1 \%$ level or better. The difference in percentage of happy households is 13 with a standard error of 4.9. If we restrict the definition of a migrant household to households claiming to have a "close" family member abroad — a spouse, parent, or child — we 
find again that families with "close" family migrant members are also statistically less happy than the families with no migrants (or only distant family as migrants) with a 12 percentage point difference in happiness and a standard error of 5.6.

Table 2

Happiness and Migration

\begin{tabular}{|c|c|c|c|c|c|}
\hline & $\mathrm{N}$ & \% Happy & Difference & SE & t-value \\
\hline No migrants in household & 115 & 78 & \multirow{2}{*}{13} & \multirow{2}{*}{4.9} & \multirow{2}{*}{$2.74^{\star \star *}$} \\
\hline $\begin{array}{l}\text { Household has one or more } \\
\text { distant or close family members } \\
\text { who is a migrant }\end{array}$ & 362 & 65 & & & \\
\hline No close migrants in household & 396 & 70 & \multirow{2}{*}{12} & \multirow{2}{*}{5.6} & \multirow{2}{*}{$2.10^{\star \star}$} \\
\hline $\begin{array}{l}\text { Family has one or more } \\
\text { close family members who } \\
\text { is a migrant }\end{array}$ & 81 & 58 & & & \\
\hline
\end{tabular}

Note: Happy is defined as reporting to be very satisfied or satisfied with life.

While the results of Table 2 suggest that migration of family members does impact the household negatively by reducing levels of happiness, such a conclusion is not necessarily warranted. Households that have migrant member could be inherently less happy and that would mean that there is no causal relationship from migration to happiness. Hence, we move on to more conclusively determine whether migration causes unhappiness by using the matching method described earlier.

\section{Results}

For our "migration experiment" we first estimate a probit model to explain migration using the full sample. The probit model is used to obtain propensity scores in order to match controls to treated observations. The model is as follows:

$$
M_{i}=\alpha_{1}+\beta^{M} F_{i}+\varepsilon_{i}
$$

where $M_{i}$ is a dummy variable assuming the value " 1 " if the head of household $i$ claims at least one parent, child, or spouse living abroad. The vector $F_{i}$ represents 
the set of head and household characteristics which predicts households' status with respect to migration. We include in this vector the head's age and its square (to allow for non-linear life-cycle effects), marital status of the head, his or her schooling, gender, and race/ethnicity. We restrict the probit to these right hand side variables because they are most likely to satisfy the exogeneity condition - that they predict migration but that migration does not, in turn, influence these variables. For example, while race may help predict which households send migrants abroad, migration of a family member does not change the race of the family. In contrast, while household income may predict migration, we cannot include household income in the probit because it is likely to be influenced, should a family member emigrate. With this equation we estimate the probability that the household is a "migrant household," meaning that the head claims to have a family member who is currently an international migrant.

At this juncture, a comment is in order regarding the definition of the dependent variable, "migrant household." We limit migrant households to household heads claiming to have a spouse, parent, or child living abroad. In essence, we are limiting our definition of migrant household to those with "close" family abroad. Undoubtedly, "close" is rather arbitrarily defined. We include parents but not siblings. However, given the pervasiveness of migration in this community ( $75 \%$ of all households surveyed claim to have a relative abroad) and given that all respondents are at least 18 years old, we felt that restricting "close family members" to parents, children, and spouses is justifiable by way of reasoning that there is a qualitative difference between having, say, a spouse abroad versus a cousin abroad. Using this narrower definition, 16 percent of households in Cuenca are migrant households.

Some simple descriptive statistics summarizing the sample variables used for this analysis are displayed in the appendix. The average household head in this survey is 41 years of age and households on average consist of 4.3 members. Sixtythree percent of household heads claim to be married (or partnered), 45 percent work full time, and 44 percent are self employed. Education is coded into 7 categories with the data revealing that on average household heads in this survey have some secondary schooling. Per capita income in this community averages US \$1,637. Most household heads are mestizo and 11 percent are white.

The results of estimation of equation (2), the probit equation used to obtain predicted probabilities of being a migrant household, is displayed in Table 3 and indicates that older heads are less likely to claim a migrant household member. In this population, migration selects negatively on schooling. An additional step in the 7 
category schooling variable reduces the likelihood of having a close family member abroad by 4 percentage points at the mean.

\section{Table 3}

Probit to Predict that the Respondent has a close family migrant member. (Dependent variable: Respondent claims that a child, parent, or spouse is living abroad)

\begin{tabular}{lcccc}
\hline & coefficient & se & z & Marginal effect \\
\hline constant & 0.8386 & 0.5520 & 1.52 & - \\
Age & $-0.0630^{\star \star \star}$ & 0.0231 & -2.62 & -0.0143 \\
Age squared & $0.0007^{* \star \star}$ & 0.0003 & 3.08 & 0.0002 \\
Schooling & $-0.1741^{\star \star \star}$ & 0.0532 & -3.27 & -0.0397 \\
Married & -0.2024 & 0.1600 & -1.26 & -0.0476 \\
Female & 0.1586 & 0.1615 & 0.98 & 0.0351 \\
White & 0.0351 & 0.2287 & 0.15 & 0.0081 \\
Indigenous or Black & -0.8386 & 0.5341 & -1.57 & -0.1219 \\
Chi ${ }^{*}$ (prob) 38.35 (0.0000). Sample size $=443$ & & \\
Observed P (predicted P) 0.17 (0.15) & & & \\
\hline
\end{tabular}

Notes: * signifies statistically different from 0 at the $10 \%$ level or better, ${ }^{\star \star}$ signifies statistically different from 0 at the $5 \%$ level or better, ${ }^{* \star *}$ signifies statistically different from 0 at the 1 level or better. $\mathrm{N}=462$

The propensity score is used to rank all observations, both selected and not selected, into migration. These ranking are used to "match" observations (non-migrant observations) to serve as controls for the migrant sample. Given that we have 78 "close migrant households" and 384 "non-migrant households," we allow for 2 control observations per treated observation; that is we use $\mathrm{K}=2$ neighbor matching. ${ }^{10}$ We now use the set of matched controls to make comparisons with the treated group. The matched controls are presumably an appropriate comparison group to the treated except for the fact that they are not treated. Hence, we can infer causality from the treatment by simply comparing the mean values for the treated group to the mean values for the matched controls and thereby attribute differences in the two to the treatment.

Of particular concern in any study using non-experimental data is whether indeed the control group serves as a good comparison for the treated group. Can we "after the fact" demonstrate that the control group resembles the treated group in the pre-treatment time period? How accurate is our matching? Do the matched controls truely serve as counterfactuals to the treated group? To gain some insights into the comparability of the treated groups with the matched controls we report on a series 
of descriptive statistics for the groups. These are i) the treated group - migrant households; ii) the untreated group - non-migrant households; iii) the matched controls - a subset of the untreated non-migrant households - those with propensity scores closest to the scores of the treated group. The results in Table 4 reveal that in many cases there are significant differences in mean values for the treated and the untreated group. Those differences, however, get smaller and all of the significant differences disappear between the treated and matched controls. Take, for example, the case of schooling. The non-treated group has almost one year more of schooling $\left(\bar{X}_{T}-\bar{X}_{N T}=-0.82\right)$ and this difference is statistically different from zero (see Table 4, column 4). But this difference gets smaller $\left(\bar{X}_{T}-\bar{X}_{M C}=0.09\right)$ and its significance disappears when we compare the treated with the matched controls (Table 4, column 5).

\section{Table 4}

Means and Proportions for the Treated, the Not Treated and the Matched Control Groups - Migration Treatment

\begin{tabular}{lccccc}
\hline & $\begin{array}{c}\text { Treated } \\
\bar{X}_{T}\end{array}$ & $\begin{array}{c}\text { Not Treated } \\
\bar{X}_{N T}\end{array}$ & $\begin{array}{c}\text { Matched } \\
\text { Control }\end{array} \bar{X}_{M C}$ & $\left(\bar{X}_{T}-\bar{X}_{N T}\right)$ & $\left(\bar{X}_{T}-\bar{X}_{M C}\right)$ \\
\hline Age & 46.74 & 40.02 & 47.02 & $6.72^{\star \star \star}$ & -0.28 \\
Schooling & 3.86 & 4.68 & 3.77 & $-0.82^{\star \star \star}$ & 0.09 \\
Married & 0.59 & 0.64 & 0.65 & -0.05 & -0.06 \\
Per capita income & 1385 & 1743 & 1699 & -358 & -314 \\
Fulltime & 0.30 & 0.48 & 0.36 & $-0.18^{\star \star \star}$ & -0.06 \\
Household Size & 4.31 & 4.28 & 3.81 & 0.03 & -0.50 \\
Female & 0.68 & 0.62 & 0.66 & 0.06 & 0.02 \\
White & 0.14 & 0.11 & 0.18 & 0.03 & -0.04 \\
Indigenous or Black & 0.01 & 0.04 & 0.01 & -0.03 & 0.00 \\
Happiness & 0.59 & 0.72 & 0.61 & $-0.12^{\star \star}$ & -0.02 \\
\hline
\end{tabular}

Notes: ${ }^{*}$ signifies statistically different from 0 at the $10 \%$ level or better, ${ }^{\star *}$ signifies statistically different from 0 at the $5 \%$ level or better, ${ }^{\star \star \star}$ signifies statistically different from 0 at the $1 \%$ level or better.

Note that while some of the variables displayed in Table 4 correspond with the variables used to undertake the "matching" (see variables included in the probit equation), not all were included in the probit model. That is, some of the descriptive statistics in Table 2 indicate that the two groups match well along dimensions not even directly considered in the matching algorithm. For example, fulltime (employment) is not included in the probit model used to select the matched controls. None- 
theless, before matching, the difference in proportion of heads working fulltime was -0.18 and is statistically different from zero at the 1 percent level or better. After matching, the difference is only -0.06 and statistically indistinguishable from zero.

Of particular interest to us is the test of differences in mean happiness levels for respondents claiming to be in migrant households versus matched non-migrant households. That is,

$$
H_{0}: \mu_{\tau}^{H}-\mu_{M C}^{H}=0
$$

against the alternative

$$
H_{i}: \mu_{\tau}^{H}-\mu_{M C}^{H} \neq 0
$$

Results for this test are displayed in the final row of Table 4. If we simply compare migrant households to all the other non-migrant households, there is a statistically significant difference in the proportion who claim to be happy. Non-migrant households, on average, are happier. But if we instead compare the migrant households to matched controls, the difference disappears. Families with close migrants are no less or more happy than families without close migrants. Assuming that our matching procedure has successfully identified a counterfactual - a set of households similar in all characteristics with the non-migrant households with the exception of claiming to have an emigrant family member - the results indicate that the two samples, on average, experience the same level of happiness.

It is interesting that a straight comparison of households by migration status (a statistically incorrect and naïve comparison) would yield us a very different conclusion. The naïve comparison suggests that migration reduces happiness while the more comparable sample suggests otherwise, that on average the level of happiness for migrant households and non-migrant households are equal.

\section{$\overline{\text { Discussion }}$}

Our expectation was that the migration of a family member would reduce happiness levels of the family left behind. Simple descriptive statistics regarding subjective happiness levels of the heads of households that have experienced migration of a family member and of non-migrant households are consistent with that suspicion. However, such a conclusion is not necessarily warranted due to selection into migration with the implication that causality from migration to happiness cannot be 
established by simply comparing the two groups. In order to purge the data of selection biases, we use matching methods to draw a "control" group which could assign causality from migration to happiness. This exercise, however, resulted in an unexpected conclusion. There is no difference in the levels of happiness of migrant and non-migrant households. The apparent difference in happiness levels is erased once we evaluate non-migrant households who are comparable to migrant households.

Why may it be that we find no differences in the happiness levels of migrant families relative to non-migrant families? We think that this may be because we have not taken into consideration that there is a second factor that often accompanies migration that is not accounted for in our analysis. Migrant families are often the recipients of remittances from abroad. If remittances contribute toward happiness levels then it may be that, in fact, we have not been able to clearly assess the impact of migration on happiness because the household is impacted by two activities, the outmigration of family and the receipt of remittances from abroad. While the outmigration of family is expected to reduce happiness levels, the inflow of remittances might be expected to increase happiness levels and in some respects compensate for the absence of loved ones.

In order to test to see if indeed this may be the case, it would be necessary to determine whether remittances increase happiness levels. On a purely descriptive level we can divide households into those that receive remittances and those that do not, conditioned on whether they are a migrant household and compare happiness levels. This is done in Table 5. In this matrix we see that in the aggregate happiness levels are lowest for households that claim a migrant member yet do not receive remittances - only 52 percent claim to be happy. In contrast, households with migrant members but who receive remittances, display more happiness in the aggregate (59 percent are happy), suggesting that there is some tradeoff between the physical presence of a family member and the receipt of remittances. Remittances may be compensating for the absence of a loved one.

\section{Table 5}

\section{Happiness levels by migrant household and remittance recipient}

\begin{tabular}{lcc}
\hline & $\begin{array}{c}\text { Percent of Migrant } \\
\text { Households } \\
\text { claiming to be happy }\end{array}$ & $\begin{array}{c}\text { Percent of non-Migrant } \\
\text { Households } \\
\text { claiming to be happy }\end{array}$ \\
\hline Receives remittances & 59 & 56 \\
Does not receive remittances & 52 & 73 \\
\hline
\end{tabular}


In an ideal world, we could separately test for the impact of remittances and migration on happiness. But in order to do so we would need considerably more information both on the household and on the migrant. Given the lack of data, it is not possible to statistically establish separate effects of remittances and migration on happiness and hence, we can only speculate on their different impacts. We are limited to assessing how migrant families are, broadly speaking, affected by some combination of migration and remittances.

There are, of course, other possible explanations for finding no differences in subjective well-being with respect to the migrant and matched control groups. Our sample size may be too small or bias may persist. It might also be the case that some households' subjective well being is enhanced with migration while others are reduced. For example, migrant household who have experienced the emigration of children may report that they are unhappy, while those who's spouse has emigrated might report instead that they are happy. The two impacts may be cancelling out in the average statistics that we compare.

\section{Conclusions}

In this paper we set out to study the impact of migration on the happiness of the family left behind. We exploit the results of a survey conducted in Cuenca, Ecuador in 2006 that collects information on the subjective well-being of the family head along with migration related variables for the family. As such, this survey allows us to explore the impacts of migration on subjective well being.

As in any study of happiness, the primary challenge is to correct for endogeneity. Given selectivity in terms of who migrates, unobserved heterogeneity is likely to complicate the assessment of migration on happiness. Dealing with this endogeneity is essential if we are to obtain credible and reliable results. In our case, we choose to deal with the endogeneity by using matching methods. To assess the impact of migration on happiness we first estimated a propensity score for migration. These scores were then used to find matched controls for those observations that were "treated" with migration.

While we attempt to solve the endogeneity problem by using matching methods, we note a second challenge to studying the impact of migration on happiness. This has to do with the fact that when communities are touched by migration, a second phenomenon occurrs simultaneously. Remittances, a by-product of migration, often (but not always) flow to the family back home. Now, if migration and remittances always take place together, it would not matter and measuring the ef- 
fect of one would provide us with ample understanding of how this phenomenon in the aggregate impacts households. However, while it is true that remittances often follow migration, it is not the case that all migrant households receive remittances. Similarly, households that receive remittances are not necessarily migrant households (using our definition of a migrant household). 1n fact, in our sample, 17 percent of households are migrant household while 28 percent of households receive remittances. There are, evidently, many households who receive remittances from (presumably) distant relatives and friends.

Thus, we make a number of tentative conclusions. First, households that claim to have migrant members seem to differ from households that do not have migrant members, complicating any assessment into how migration affects happiness levels. This selection into migration seems to account for at least some of the differences in average levels of happiness observed in the migrant and non-migrant household groups. That is, the observed discrepancy in happiness levels between migrant and non-migrant households seems to be due, at least in part, to inherent differences in these two groups. Second, some migrant households receive no remittances from their family abroad while others do. We tentatively suggest that happiness levels differ for migrant households according to whether they receive remittances from abroad or not. Migrant households that receive remittances may report greater satisfaction than those migrant households that do not receive remittances. It may be that remittances, to some degree, "compensate" migrant households who are less happy explaining why we observe no differences in happiness levels across the two groups of households.

What is the mechanism by which remittances raise happiness levels? Is it because the monetary transfers truly compensate for the absence of the loved one? Or are the remittances a re-affirmation of the loyalties of a now absent household member? Our analysis cannot answer these questions. But we note that the close link between migration and remittances and the disentangling of the two is an important issue for migration scholars to tackle in order for us to obtain a more accurate assessment of the effects of international migration on households around the globe.

\section{Notes}

\section{Corresponding author}

2. According to the United Nation's population database, world population in 2005 stood at 6.5 billion (United Nations, World Population Prospects: The 2008 Revisions). In the same year, the United Nations estimated that there were 195 million migrants (United Nations, Trends in International Migrant Stock: The 2008 Revision). 
3. See UNDP (1999) for more on this point. It should also be noted that over the longer run it is conceivable that technological innovations reduce migration. Technology may facilitate that work take place across international borders without the need for workers to move abroad to take advantage of work opportunities.

4. Almost all households in San Fernando are migrant households. As will become evident in the methodology section of this paper, it is not possible to employ the methodology we use for households residing in San Fernando since there are too few non-migrant households to draw from to obtain our counterfactual comparison group.

5. In this paper we will refer to those responding that they are satisfied with live as "happy" and those not satisfied with life as "unhappy". Note that using the terminology - happy or unhappy - as synonymous with being satisfied or not with life is not strictly appropriate. As a referee pointed out, "just the fact that somebody is 'satisfied with life' doesn't translate into a happy person. The person may be, for instance, resigned to live a life of misery." We use the term "happy" as a convenience and ask the reader to note this convention in this paper.

6. The exact wording for this question in the original is: ¿En términos generales, usted diría que está muy satisfecho con su vida, bastante satisfecho con su vida, no muy satisfecho o para nada satisfecho?

7. The received wisdom is that there is considerable selectivity with respect to a host of migrant characteristics (See Chiquiar and Hanson (2005) and Feliciano (2005) for examples). This selectivity is likely to spillover into the characteristics embodied by the households from which the migrants originate.

8. While migration experiments tend to be rare, there are several important exceptions. For a few examples see Stillman, McKenzie, and Gibson (2009) and Aycinema, Martinez, and Yang (2009).

9. Recall, non-migrant households may have migrants, but they are not "close" family members. A cousin, for example, is not defined to be a close family member in this paper.

10. Our results remain mostly intact when we allow for only 1 matched observation per treated observation. 


\section{References}

Aycinema, D., Martinez, C. A., \& Yang, D. (2009). The impact of remittances fees on remittance flows: Evidence from a field experiment among Salvadorian migrants (Unpublished manuscript). University of Michigan.

Blanchflower, D., \& Oswald, A. J. (2000). Well-being over time in Britain and the USA. NBER working paper \# 7487.

Borjas, G. (2002). Homeownership in the immigrant population. Journal of Urban Economics, 52(3), 448-76.

Card, D. (2005). Is the new immigration really so bad? Economic Journal, 115(507), F300-F323.

Cárdenas, M., Di Maro, V., \& Sorkin, I. (2009). Migration and life satisfaction: Evidence from Latin America. Journal of Business Strategies, 26(1), 9-34.

Chiquiar, D., \& Hanson, G. H. (2005). International migration, self-selection, and the distribution of wages: Evidence from Mexico and the United States. Journal of Political Economy, 113(2), 239-281.

Chiswick, B. (2002). Speaking, reading, and earnings among low-skilled immigrants. In K. F. Zimmermann \& T. Bauer (Eds.), The economics of migration, Volume 2. Assimilation of migrants (pp. 429-50). Cheltenham, UK and Northampton, MA: Elgar.

Clark, A. E., \& Oswald, A. J. (1994). Unhappiness and unemployment. Economic Journal, 104(424), 648-59.

Davidson, R. J. (2000). Affective style, psychopathology, and resilience: Brain mechanisms and plasticity. American Psychologist, 55(11), 1196-1214.

DiTella, R., \& MacCulloch, R. (2005). Partisan social happiness. Review of Economics Studies, 72(2), 367-393.

Easterlin, R. (1974). Does economic growth improve the human lot? Some empirical evidence. In P. A. David \& M. W. Reder (Eds.), Nations and Households in Economic Growth: Essays in Honor of Moses Abromowitz (pp. 89-125). New York: Academic Press.

Easterlin, R. (2001). Income and happiness: Toward a unified theory. Economic Journal, III(473), 465-84.

Feliciano, C. (2005). Educational selectivity in U.S. immigration: How do immigrants compare to those left behind? Demography, 42(1), 131-152.

Frank, R. (1985). Choosing the right pond. New York: Oxford University Press.

Gatton, B. (2005). Ecuador en la historia de la migración internacional ¿Modelo o aberración? In G. Herrera, M. C. Carrillo, \& A. Torres, (Eds.), La migración ecuatoriana: transnacionalismo, redes e identidades. Quito, Ecuador: FLASCO. 
Graham, C., \& Pettinato, S. (2001). Happiness, markets and democracy: Latin America in comparative perspective. Journal of Happiness Studies, 2(3), 237-268.

Hartlog, J., \& Oosterbeek, H. (1997). Health, wealth, and happiness: Why pursue a higher education? Working Paper. Department of Economics, University of Amsterdam.

International Organization for Migration. (2005). Costs and benefits of international migration. World Migration Report 2005 (p. 379). Geneva: International Organization for Migration.

Layard, R. (2005)."Happiness and public policy. Discussion Paper N 14, LSE.

Leuven, E., \& Sianesi, B. (2003). PSMATCH2: Stata module to perform full mahalanobis and propensity score matching, common support graphing, and covariate imbalance testing. Retrieved from http://ideas.repec.org/c/boc/bocode/ s432001.htmI.

Massey, D. (2006, April 4,). The wall that keeps illegal workers in. New York Times, p. 23.

Miles, D., \& Rossi, M. (2005). Learning about ones' relative position and subjective well-being. Applied Economics, 39(13), 1711-18.

Pavot, W., Diener, E., Colvin, C., \& Sandvik, E. (1991). Further validation of the satisfaction with life scale: Evidence for the cross-method convergence of wellbeing measures. Journal of Personality Assessment, 57(I), 149-161.

Rayo, L., \& Becker, G. (2007). Habits, peers, and happiness: an evolutionary perspective. American Economic Review, 97(2), 487-491.

Rosenbaum, P., \&d Rubin, D. (1983). The central role of the propensity score in observational studies for causal effects. Biometrika, 70(1), 41-55.

Stillman, Sn, McKenzie, D., d Gibson, J. (2009). Migration and mental health: Evidence from a natural experiment. Journal of Health Economics, 2(3), 677-87.

Soruco, X., Piani, G., d Rossi, M, (2006). What emigration leaves behind. The situation of emigrants 'families in Ecuado. Fundación Sur, Ecuador, and dECON, Uruguay. Mimeo.

Smith, J. (2003). Assimilation across the Latino generations. American Economic Review, 93(2), 315-319.

UNDP, (1999), United Nations Development Programme, Human Development Report.

United Nations, Department of Economic and Social Affairs, Population Division. (2009). Trends in international migrant stock: The 2008 revision. (United Nations database, POP/DB/MIG/Stock/Rev.200). 
United Nations, Department of Economic and Social Affairs, Population Division. (2009). World population prospects: The 2008 revisions. Retrieved from (United Nations Database, http://esa.un.org/unpp/index.asp?panel=1)

\section{Appendix}

Descriptive Statistics for variables discussed and used in the analysis

Cuenca, Ecuador, 2006

\begin{tabular}{lcccc}
\hline Variable & Mean & $\begin{array}{c}\text { Standard } \\
\text { deviation }\end{array}$ & Minimum & Maximum \\
\hline Happiness & 0.68 & 0.47 & 0 & 1 \\
Age & 41.12 & 16.65 & 18 & 86 \\
Schooling & 4.46 & 1.57 & 1 & 7 \\
Fulltime & 0.45 & 0.49 & 0 & 1 \\
Self employed & 0.44 & 0.49 & 0 & 1 \\
Married (or partnered) & 0.63 & 0.48 & 0 & 1 \\
Household size & 4.29 & 2.06 & 1 & 15 \\
Per Capita income & 1637 & 1823 & 0 & 13200 \\
"Migrant" household & 0.76 & 0.43 & 0 & 1 \\
"Close migrant" household & 0.17 & 0.37 & 0 & 1 \\
Black household & 0.00 & 0.07 & 0 & 1 \\
Indigenous household & 0.03 & 0.18 & 0 & 1 \\
Mestizo household & 0.85 & 0.36 & 0 & 1 \\
White household & 0.11 & 0.31 & 0 & 1 \\
Receives remittances & 0.28 & 0.45 & 0 & 1 \\
\hline Notes: 478 households, fom & Ditan
\end{tabular}

Notes: 478 households, from Discrimination and Economic Outcomes Survey, Latin American and Caribbean Research Network, Inter-American Development Bank.

\section{Bigraphical Sketch of Authors}

Fernando Borraz holds the title of Senior Researcher at the Banco Central del Uruguay and Universidad de la República, Unuguay. His research is in applied microeconometrics. He has published in Cuadernos de Economia, Well-Being and Social Policy, Global Economy Journal, and Journal of Economic Development. In 2004, he received the National Prize in Economics (first prize) awarded by the Universidad de la República. He earned his Ph. D. in Economics from Georgetown University, USA.

Susan Pozo is a Professor of Economics at Western Michigan University, Kalamazoo (MI). She has published numerous articles on migration, remittances, 
and international finance in reputed journals including American Economic Review, Applied Economics, Applied Financial Economics, Harvard International Review, International Migration Review, International Review of Economics and Finance, Journal of Development Studies, Journal of International Money and Finance, Journal of Macroeconomics, Journal of Population Economics, Review of Development Economics, Review of Economics and Statistics, Review of International Economics, Southern Economic Journal, World Development, and World Economy. She earned her Ph.D. in Economics from Michigan State University, East Lansing (MI). Maximo Rossi is a Professor of Microeconomics at the Universidad de la República, Uruguay. He has published articles in Applied Economics, International Journal of Public Opinion Research, Journal of Applied Economics, Journal of Money, Credit and Banking, and Trimestre Económico among others. He holds a Ph.D. in Economics from the Universidad de Granada, Spain. 
